\title{
Influence of Land Use and Land Cover Change on Land surface temperature
}

\author{
Jing $\operatorname{Sun}^{1 *}$, and Jing $\mathrm{He}^{1}$ \\ ${ }^{1}$ Department of Geographic Information Science, Tongling University, Tongling, Anhui, 244061, China
}

\begin{abstract}
The rapid urbanization process has recently led to significant land use and land cover (LULC) changes, thereby affecting the climate and the environment. The purpose of this study is to analyze the LULC changes in Hefei City, Anhui Province, and their relationship with land surface temperature (LST). To achieve this goal, multitemporal Landsat data were used to monitor the LULC and LST between 2005 and 2015. The study also used correlation analysis to analyze the relationship between LST, LULC, and other spectral indices (NDVI, NDBI, and NDWI). The results show that the built-up land has expanded significantly, transforming from $488.26 \mathrm{~km}^{2}$ in 2005 to $575.64 \mathrm{~km}^{2}$ in 2015. It further shows that the mean LST in Hefei city has increased from $284.0 \mathrm{~K}$ in 2005 to $285.86 \mathrm{~K}$ in 2015 . The results also indicate that there is a positive correlation between LST and NDVI and NDBI, while there is a negative correlation between LST and NDWI. This means that urban expansion and reduced water bodies will lead to an increase in LST.
\end{abstract}

\section{Introduction}

With the development of the economy, the urban population has grown rapidly, which has promoted rapid urbanization. Land use and land cover (LULC) patterns have undergone tremendous changes, as well as changes in various biophysical climatic conditions, especially urban land surface temperature (LST) [1,2]. The conversion of LULC (such as wetlands, vegetation, and agricultural areas) to impervious land can greatly affect LST [3]. LST is regularly measured from satellite sensors with medium spatial scale and high temporal resolution (such as Landsat). Generally, the LST data derived from the satellite's thermal infrared (TIR) band is a key variable to understand the impact of changes in LULC caused by urbanization [4]. Spectral indices from remote sensing data can usually provide a comprehensive understanding of the relationship between LST and LULC conditions $[5,6]$. The most common satellite-derived indicators for estimating the temporal and spatial changes of LST are the normalized difference vegetation index (NDVI), the normalized difference built-up index (NDBI), and the normalized difference water index (NDWI) [7]. Previous studies have analyzed the different relationships between LULC, LST, NDVI, NDBI, and NDWI [7-13]. These results are mainly attributable to the growth and expansion of cities brought about by urbanization and socioeconomic development, which affect land use and regional climate change.

This study aims to monitor and analyze the spatiotemporal trends of LULC changes and establish their relationship with the LST changes of Hefei city, China. More specifically, the study seeks to: (a) map and analyze the various changes in the LULC pattern of Hefei city from 2005 to 2015; (b) study the distribution of LST, NDVI, NDBI, and NDWI of the Hefei city; (c) analyze the relationship of LST and indices (NDVI, NDBI, and NDWI).

\section{Materials and Methods}

\subsection{Study Area}

Hefei city is the largest and capital city of Anhui Province, China, which comprises four urban districts, one countylevel city, and four counties. In this study, four urban districts were chosen as the study area, which covers an area of $1308 \mathrm{~km}^{2}$ and is situated between $116^{\circ} 51^{\prime}$ $117^{\circ} 26^{\prime} \mathrm{E}$ and $31^{\circ} 38^{\prime}-32^{\circ} 4^{\prime}$ N. (Figure 1).

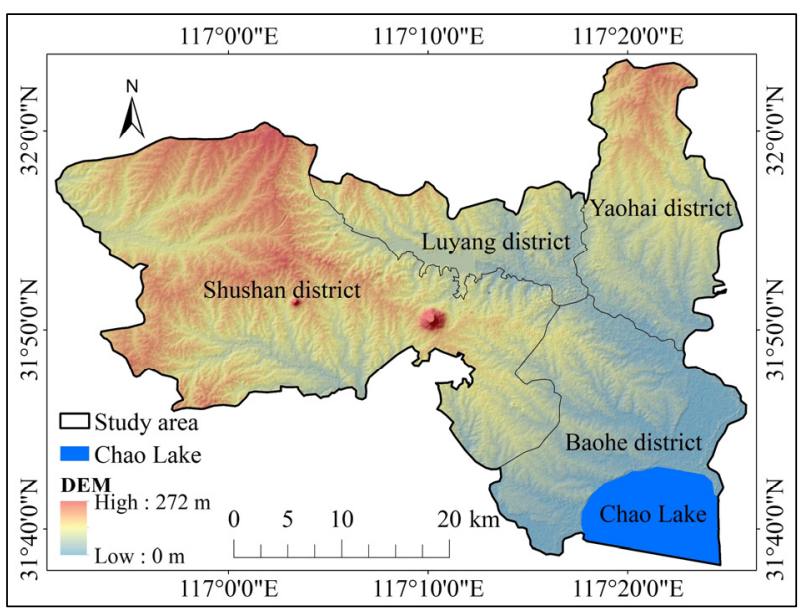

Figure 1. Location map of the study area. 


\subsection{Datasets}

To identify the changes in LULC, the Landsat 5/7/8 images of Level-1 products for Worldwide Reference System-2 with Path 121 Row 38 on 5 March 2005, 11 March 2010, and 1 March 2015, were downloaded through the United States Geological Survey online portal (www.earthexplore.usgs.gov). Auxiliary data in the form of reference maps were obtained from Google Earth imagery. The MOD05_L2 product of MODIS/Terra on the same day with the Landsat data was downloaded from LAADS DAAC (https://ladsweb.modaps.eosdis.nasa.gov/).

\subsection{Research Methodology}

The methodological flow chart illustrated in Figure 2 summarizes the several procedures used in this study.

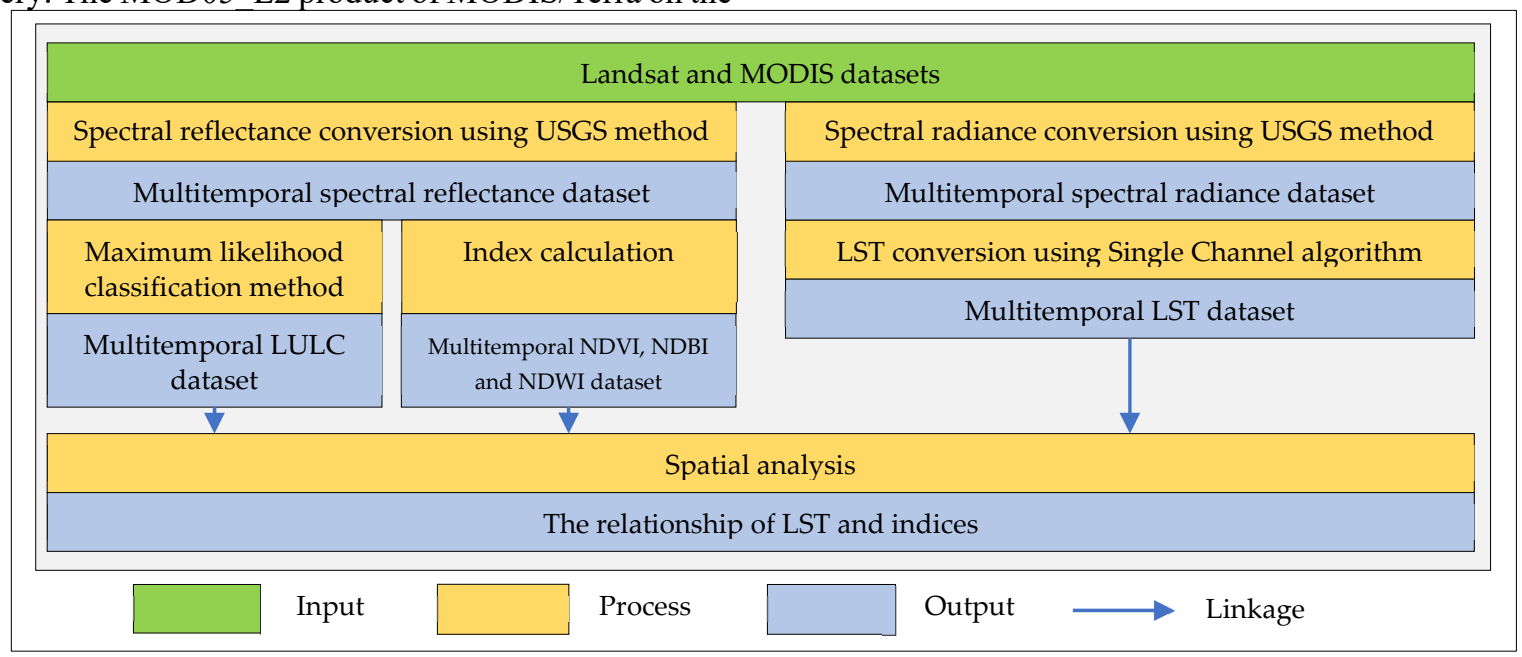

Figure 2. Methodological flow chart of the study.

\subsubsection{LULC Classification}

The maximum likelihood classification (MLC) method is one of the most widely used LULC classification methods due to its high classification accuracy $[14,15]$. In this study, the MLC method was used to divide the LULC in 2005, 2010, and 2015 into four categories, including built-up land, agricultural land, forest land, and water bodies.

\subsubsection{Accuracy Assessment}

The standard thematic accuracy assessment was adopted using overall accuracy (OA), and Kappa hat (KH) coefficient based on error matrix between classified LULC data and ground reference information data [16]. For thematic accuracy assessment, the number of samples was estimated based on the multinomial distribution $[16,17]$, and sample points were allocated for thematic accuracy assessment using a stratified random sampling technique.

\subsubsection{NDVI, NDBI, and NDWI Estimation}

The NDVI, NDBI, and NDWI are the most used indicators in environmental studies, which were applied to extracting vegetation conditions, impervious surfaces, and water bodies from remotely sensed data, respectively. These indices were estimated using Equation (1) to Equation (3) [7].

$$
\begin{gathered}
N D V I=(N I R-R e d) /(N I R+R e d) \\
N D B I=(\text { SWIR } 1-N I R) /(S W I R 1+N I R)(2) \\
N D W I=(\text { Green }-N I R) /(\text { Green }+N I R)(3)
\end{gathered}
$$

\subsubsection{LST Retrieval}

The TIR bands from Landsat 5/7/8 were used to retrieve LST through a single channel (SC) algorithm. The process to retrieve LST is discussed below.

(1) Brightness temperature calculation

DNs of the TIR band of Landsat images were converted to spectral radiance using the radiance scaling factors provided in the metadata file. Then the brightness temperature (BT), which is the effective temperature viewed by the satellite under an assumption of unity emissivity, can be converted from spectral radiance with the following formula [1]:

$$
\begin{gathered}
L_{\lambda}=M_{L} \cdot Q_{\text {cal }}+A_{L} \\
T=K_{2} \cdot\left(\ln \left(\frac{K_{1}}{L_{\lambda}}+1\right)\right)^{-1}
\end{gathered}
$$

where, $L_{\lambda}$ is the spectral radiance $\left(\mathrm{W} /\left(\mathrm{m}^{2} \cdot \mathrm{sr} \cdot \mu \mathrm{m}\right)\right), M_{L}$ is the radiance multiplicative scaling factor, $A_{\lambda}$ is the radiance additive scaling factor, $Q_{c a l}$ is the pixel value in $\mathrm{DN}, T$ is BT in Kelvin $(\mathrm{K}), K_{1}$, and $K_{2}$ are the thermal conversion constants.

(2) Emissivity extraction

In this study, the NDVI threshold method [18] were adopted to estimate the emissivity of different land surfaces as follows: 


$$
\varepsilon=\left\{\begin{array}{cc}
\varepsilon_{w} & N D V I \leq 0 \\
\varepsilon_{s} & 0<N D V I<N D V I_{s} \\
\varepsilon_{v} \cdot P_{v}+\varepsilon_{s} \cdot\left(1-P_{v}\right)+\left(1-\varepsilon_{s}\right) \cdot \varepsilon_{v} \cdot F^{\prime} \cdot\left(1-P_{v}\right) & N D V I_{s} \leq N D V I \leq N D V I_{v} \\
\varepsilon_{v} \cdot P_{v}+\left(1-\varepsilon_{s}\right) \cdot \varepsilon_{v} \cdot F^{\prime} \cdot\left(1-P_{v}\right) & N D V I>N D V I_{v}
\end{array}\right.
$$

where, $\varepsilon$ is the band emissivity, $\varepsilon_{v}$ and $\varepsilon_{s}$ are the emissivities of vegetation and soil, respectively, $P_{v}$ is the proportion of vegetation, $N D V I_{v}$ and $N D V I_{S}$ are the $N D V I$ for a fully vegetated pixel and a soil one, respectively, and $F^{\prime}$ is a geometrical factor ranging between 0 and 1 .

(3) Water vapor content extraction

MODIS Reprojection Tool and MRTSwath tool were used for reprojection and conversion of MODIS product to $\mathrm{DN}$ values of water vapor content. To retrieve the real value of water vapor content, the $\mathrm{DN}$ values were divided by the scaling factor (scaling factor $=1000$ ).

(4) Land surface temperature derivation

The SC algorithm provided by Jiménez-Muñoz and Sobrino [19] was chosen for LST retrieval from Landsat data using the following Equation (7):

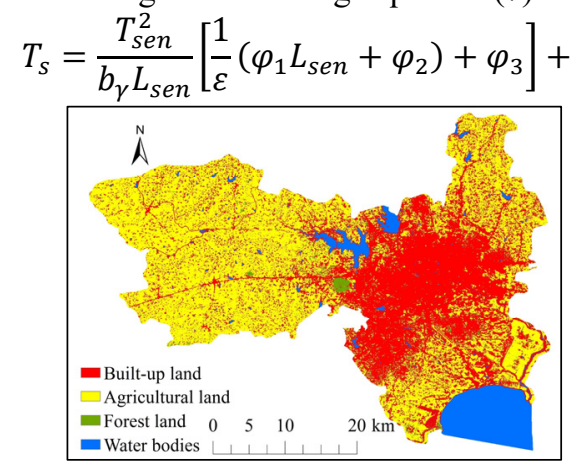

(a) where, $T_{s}$ is the land surface temperature, $\varepsilon$ is the surface emissivity, $T_{\text {sen }}$ is the at-sensor BT; $b_{\gamma}=c_{2} / \lambda$; and $\varphi_{1}, \varphi_{2}$, and $\varphi_{3}$ are the atmospheric functions which can be obtained as a function of the total atmospheric water vapor content $(w)$ [20-22].

\section{Results \& Discussion}

\subsection{LULC Classification and Change Detection}

The classified LULC maps of Hefei city are presented in Figure 3 and quantified in Table 1. These classes comprise built-up land (B), agricultural land (A), forest land (F), and water bodies(W).

Figure 3. Classified LULC of Hefei city in; (a) 2005, (b) 2010, and (c) 2015.

Table 1. LULC distribution in 2005, 2010, and 2015.

\begin{tabular}{ccccccc}
\hline \multirow{2}{*}{ LULC Types } & \multicolumn{2}{c}{$\mathbf{2 0 0 5}$} & \multicolumn{2}{c}{$\mathbf{2 0 1 0}$} & \multicolumn{2}{c}{$\mathbf{2 0 1 5}$} \\
\cline { 2 - 7 } & Area (sq. km) & Area (\%) & Area (sq. km) & Area (\%) & Area (sq. km) & Area (\%) \\
\hline Built-up land & 488.26 & 37.31 & 504.16 & 38.53 & 575.64 & 43.99 \\
Agricultural land & 692.84 & 52.95 & 651.77 & 49.81 & 625.01 & 47.76 \\
Forest land & 21.88 & 1.67 & 35.82 & 2.74 & 8.14 & 0.62 \\
Water bodies & 105.57 & 8.07 & 116.80 & 8.93 & 105.33 & 8.05 \\
\hline Total & 1308.56 & 100.00 & 1308.56 & 100.00 & 1308.56 & 100.00 \\
\hline
\end{tabular}

The result reveals that the built-up land has expanded from $488.26 \mathrm{~km}^{2}(37.31 \%)$ in 2005 to $575.64 \mathrm{~km}^{2}(43.99 \%)$ in 2015 as the most one among the four LULC types in Hefei city. However, the agricultural land and forest land decreased from $692.84 \mathrm{~km}^{2}(52.95 \%)$ and $21.88 \mathrm{~km}^{2}$ $(1.67 \%)$ in 2005 to $625.01 \mathrm{~km}^{2}(47.76 \%)$ and $8.14 \mathrm{~km}^{2}$ $(0.62 \%)$ in 2015 , respectively. Meanwhile, the water bodies remained basically unchanged. The gradual increase in built-up land and decrease in agricultural land can be attributed to urban growth. It can be seen from the LULC classification and change detection that the urbanization process of Hefei may be an important factor in the transition from the natural surface to the built-up land.

\subsection{Accuracy Assessment of LULC Classification}

In this study, 443 sample points based on the multinomial distribution with the desired precision of $5 \%$ and a level of confidence of $85 \%$ were applied to access thematic accuracy assessment. Table 2 shows the error matrix and accuracy of LULC classification in 2005, 2010, and 2015. The $\mathrm{OA}$ and $\mathrm{KH}$ of the three maps were above $87 \%$, and 0.8 , which signifies a reliable LULC classification [23]. 
Table 2. Error matrix of 2005, 2010, and 2015.

\begin{tabular}{|c|c|c|c|c|c|c|c|c|c|c|c|c|c|c|}
\hline \multicolumn{5}{|c|}{ (a) 2005 Error Matrix } & \multicolumn{5}{|c|}{ (b) 2010 Error Matrix } & \multicolumn{5}{|c|}{ (c) 2015 Error Matrix } \\
\hline LULC Types & B & A & $\mathbf{F}$ & W & LULC Types & $\mathbf{B}$ & $\mathbf{A}$ & $\mathbf{F}$ & $\mathbf{W}$ & LULC Types & $\mathbf{B}$ & $\mathbf{A}$ & $\mathbf{F}$ & $\mathbf{W}$ \\
\hline $\mathrm{B}$ & 59 & 14 & 3 & 2 & B & 89 & 13 & 2 & 1 & B & 129 & 11 & 5 & 1 \\
\hline A & 4 & 277 & 5 & 4 & A & 13 & 239 & 5 & 2 & A & 10 & 194 & 4 & 2 \\
\hline $\mathrm{F}$ & 3 & 5 & 15 & 2 & $\mathrm{~F}$ & 2 & 4 & 18 & 1 & $\mathrm{~F}$ & 4 & 5 & 15 & 1 \\
\hline W & 1 & 1 & 0 & 48 & W & 1 & 2 & 2 & 49 & W & 1 & 3 & 0 & 48 \\
\hline $\mathrm{OA}$ & \multicolumn{4}{|c|}{$90.1 \%$} & $\mathrm{OA}$ & \multicolumn{4}{|c|}{$89.2 \%$} & $\mathrm{OA}$ & \multicolumn{4}{|c|}{$87.1 \%$} \\
\hline $\mathrm{KH}$ & \multicolumn{4}{|c|}{0.808} & KA & \multicolumn{4}{|c|}{0.815} & KA & \multicolumn{4}{|c|}{0.802} \\
\hline
\end{tabular}

\subsection{LST Distribution}

The spatial distribution of LST of Hefei city in 2005, 2010, and 2015 were illustrated in Figure 4. The results indicate that the LST of Hefei city ranged between approximately 277.45-287.16 K, 272.77-290.66 K, and 279.63-288.86 K in 2005, 2010, and 2015, respectively. Meantime, the mean LST were approximately 284.01, 286.69, and
285.86 in 2005,2010 , and 2015, respectively. The LST analysis indicates that the mean LST of the Hefei city has increased by $2.68 \mathrm{~K}$ from 2005 to 2015 . Furthermore, the mean LST decreased by $0.83 \mathrm{~K}$ from 2010 to 2015 since the data acquisition date in 2015 was 10 days earlier than in 2010. In general, the mean LST in Hefei city increased by1.85 K from 2005 to 2015 .

The development of urban land has led to an increase in land surface temperature in Hefei, which is consistent with previous studies [24].

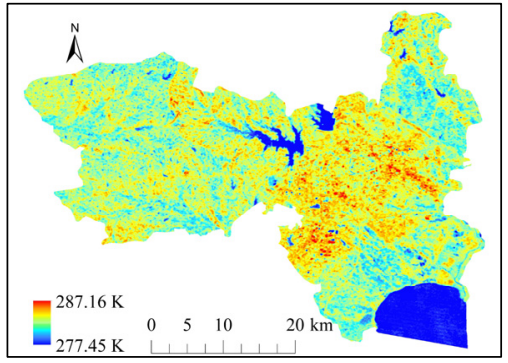

(a)

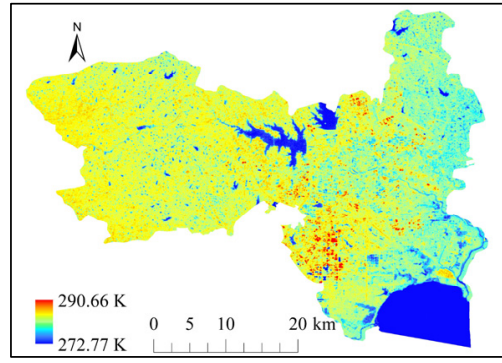

(b)

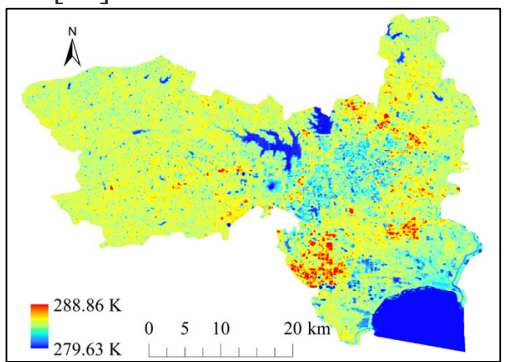

(c)

Figure 4. LST distribution of Hefei city in; (a) 2005, (b) 2010, and (c) 2015.

\subsection{NDVI, NDBI, and NDWI Distribution and Their Relationship with LST}

The distribution of NDVI of Hefei city in 2005, 2010, and 2015 , is presented in Figure 5. The result indicates that the NDVI values ranged between -0.3930 to 0.5963 in 2005 , -0.4286 to 0.4790 in 2010, and -0.3610 to 0.6386 in 2015 . The results demonstrate the highest NDVI in the west and north-eastern part of Hefei city, mainly covered by forest land and agricultural land. The distribution of NDBI of
Hefei city in 2005, 2010, and 2015 is presented in Figure 6. The result indicates that the NDBI values ranged between -0.8517 to 0.5966 in $2005,-0.6429$ to 0.5283 in 2010, and -0.6811 to 0.4768 in 2015 . The built-up land in the center of Hefei city has a higher NDBI while the water bodies have a lower NDBI. The distribution of NDWI of Hefei city in 2005, 2010, and 2015 is presented in Figure 7. The result demonstrates that the NDWI values ranged between -0.5022 to 0.4908 in $2005,-0.3846$ to 0.4828 in 2010 , and -0.5461 to 0.4534 in 2015 . Among them, the water bodies have the highest NDWI value.

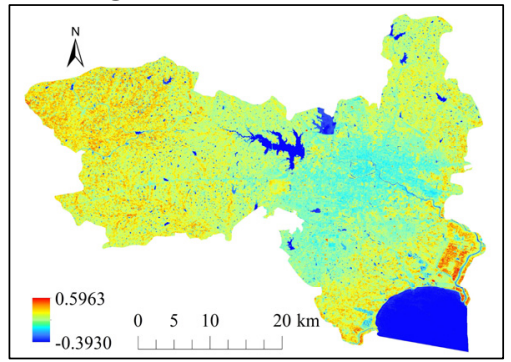

(a)

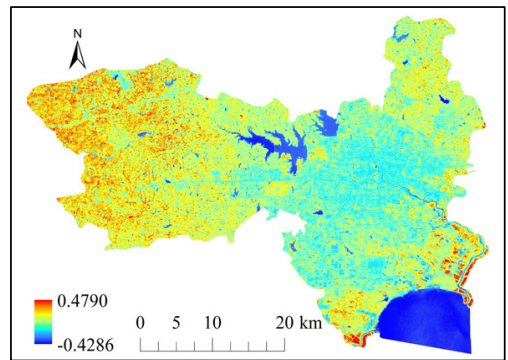

(b)

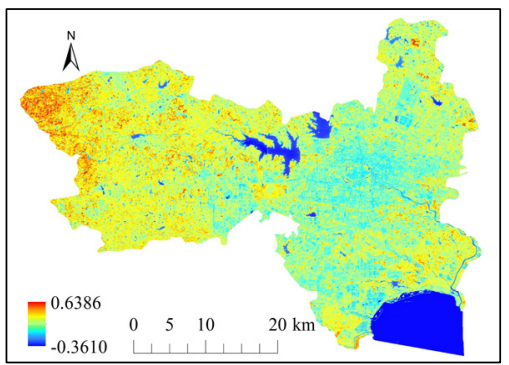

(c)

Figure 5. NDVI spatial distribution of Hefei city in: (a) 2005, (b) 2010, and (c) 2015. 


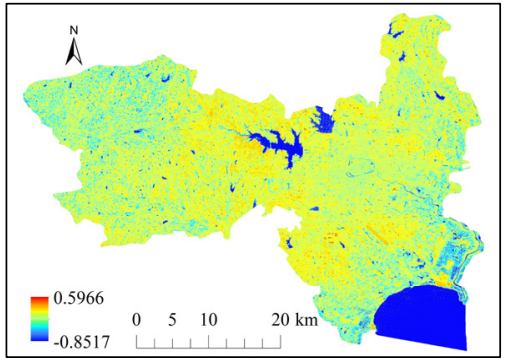

(a)

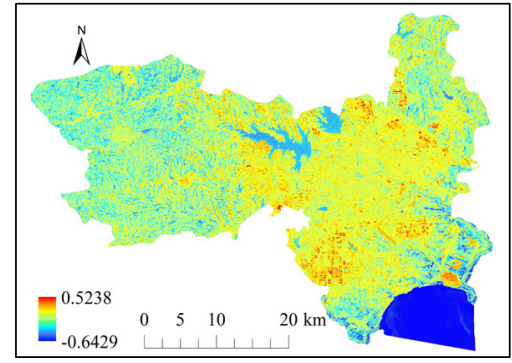

(b)

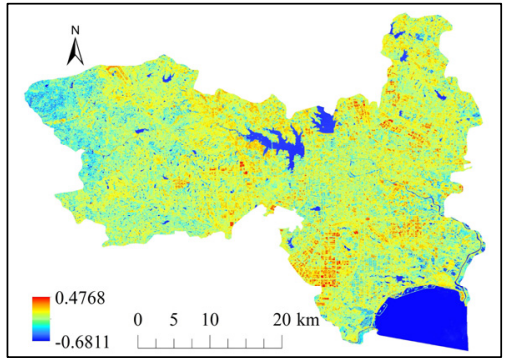

(c)

Figure 6. NDBI spatial distribution of Hefei city in: (a) 2005, (b) 2010, and (c) 2015 .

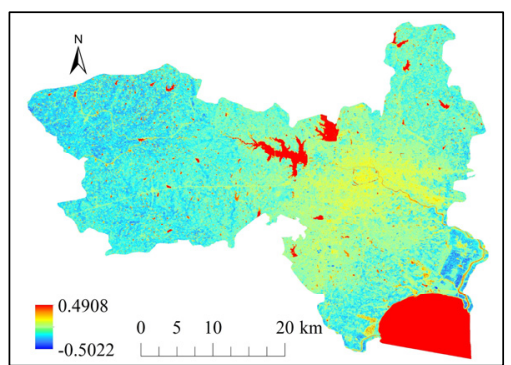

(a)

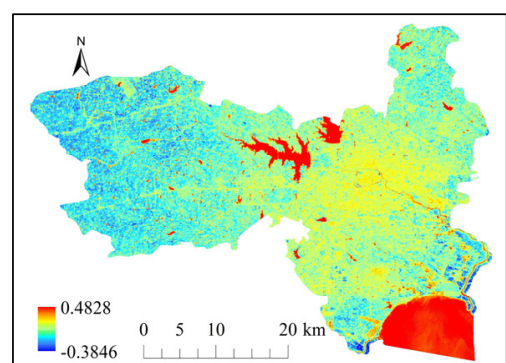

(b)

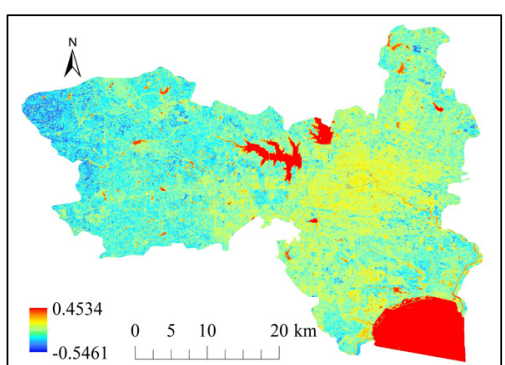

(c)

Figure 7. NDWI spatial distribution of Hefei city in: (a) 2005, (b) 2010, and (c) 2015.

To examine the relationship between NDVI, NDBI, NDWI, and LST, the correlation was calculated with the Band Collection Statistics tool in ArcGIS and the results are displayed in Table 3. It shows a positive correlation between the values of LST and NDVI and NDBI, and a negative correlation between LST and NDWI. The results indicate that lower LST values corresponded to lower NDVI (e.g., water bodies), while higher LST values corresponded to higher NDVI (e.g., agricultural land). Furthermore, the results also manifest that lower LST values corresponded to lower NDBI (e.g., water bodies), while higher LST values corresponded to higher NDBI (e.g., built-up land). In contrast, the results imply that lower LST values corresponded to higher NDWI (e.g., water bodies), while higher LST values corresponded to lower NDWI (e.g., built-up land).

Table 3. Correlation between NDVI, NDBI, NDWI and LST

\begin{tabular}{cccc}
\hline Year & NDVI and LST & NDBI and LST & NDWI and LST \\
\hline 2005 & 0.4861 & 0.7726 & -0.5903 \\
2010 & 0.6949 & 0.6553 & -0.7811 \\
2015 & 0.7123 & 0.7369 & -0.7735 \\
\hline
\end{tabular}

The positive correlation between LST and NDVI, the positive correlation between LST and NDBI, and the negative correlation between LST and NDWI conform to earlier studies. Yuan Chi et al.[8] analyzed relationships among LST and NDVI in the Yellow River Delta, China, the positive correlations were observed in all seasons of 2016-2017. Subhanil Guha et al. [11] focuses on the study of land surface temperature with NDBI using Landsat 8 OLI and TIRS data in Florence and Naples city, and LST performs a strong correlation with NDBI (positive). Bayes Ahmed et al.[25] analyzed LULC and LST in Dhaka, Bangladesh, and the results of multiple correlation and regression analyses indicate that LST presents a negative correlation with NDWI.

\section{Conclusions}

The multi-temporal Landsat satellite data was used to analyze the spatiotemporal impact of LULC changes on LST in Hefei city from 2005 to 2015 in this study. The
LULC change analysis indicates a rapid urban growth in Hefei city with a considerable built-up land increase from $488.26 \mathrm{~km} 2$ in 2005 to $575.64 \mathrm{~km} 2$ in 2015 . The LST analysis result revealed that the mean LST increased from $284.0 \mathrm{~K}$ in 2005 to $285.86 \mathrm{~K}$ in 2015 . The correlation between LST and land-use indices was also analyzed in this study. The study suggests a positive relationship between LST and NDBI while establishing a negative relationship between LST and NDWI during the different periods. This implies that higher LST is experienced along with a decline in water bodies and an increase in built-up land. The findings of this study suggest that LULC changes in Hefei city have substantially influenced LST. Consequently, the mitigation plan to reduce land surface temperature due to urbanization should be prepared by the corresponding agencies. 


\section{Acknowledgments}

This research was funded by the Natural Science Research Project of Anhui Education Department, grant number KJ2019A0707.

\section{Reference}

1. Ranagalage, M.; Estoque, R.C.; Handayani, H.H.; Zhang, X.; Morimoto, T.; Tadono, T.; Murayama, Y. Relation between Urban Volume and Land Surface Temperature: A Comparative Study of Planned and Traditional Cities in Japan. Sustainability 2018, 10, 2366.

2. Fu, P.; Weng, Q. A time series analysis of urbanization induced land use and land cover change and its impact on land surface temperature with Landsat imagery. Remote Sensing of Environment 2016, 175, 205-214.

3. Kafy, A.A.; Rahman, M.S.; Faisal, A.-A.; Hasan, M.M.; Islam, M. Modelling future land use land cover changes and their impacts on land surface temperatures in Rajshahi, Bangladesh. Remote Sensing Applications: Society and Environment 2020, $18,100314$.

4. Zhu, Z.; Woodcock, C.E. Continuous change detection and classification of land cover using all available Landsat data. Remote Sensing of Environment 2014, 144, 152-171.

5. Fu, P.; Weng, Q. Responses of urban heat island in Atlanta to different land-use scenarios. Theoretical and Applied Climatology 2018, 133, 123-135, doi:10.1007/s00704-017-2160-3.

6. Estoque, R.C.; Murayama, Y.; Myint, S.W. Effects of landscape composition and pattern on land surface temperature: An urban heat island study in the megacities of Southeast Asia. Science of The Total Environment 2017, 577, 349-359.

7. Chen, X.-L.; Zhao, H.-M.; Li, P.-X.; Yin, Z.-Y. Remote sensing image-based analysis of the relationship between urban heat island and land use/cover changes. Remote Sensing of Environment 2006, 104, 133-146.

8. Chi, Y.; Sun, J.; Sun, Y.; Liu, S.; Fu, Z. Multitemporal characterization of land surface temperature and its relationships with normalized difference vegetation index and soil moisture content in the Yellow River Delta, China. Global Ecology and Conservation 2020, 23, e01092.

9. Zhang, Y.; Odeh, I.O.A.; Han, C. Bi-temporal characterization of land surface temperature in relation to impervious surface area, NDVI and NDBI, using a sub-pixel image analysis. International Journal of Applied Earth Observation and Geoinformation 2009, 11, 256-264.

10. Yuvaraj, R.M. Extents of Predictors for Land Surface Temperature Using Multiple Regression Model. The Scientific World Journal 2020, 2020, 3958589.

11. Guha, S.; Govil, H.; Dey, A.; Gill, N. Analytical study of land surface temperature with NDVI and NDBI using Landsat 8 OLI and TIRS data in Florence and
Naples city, Italy. European Journal of Remote Sensing 2018, 51, 667-678.

12. Mirchooli, F.; Sadeghi, S.H.; Khaledi Darvishan, A. Analyzing spatial variations of relationships between Land Surface Temperature and some remotely sensed indices in different land uses. Remote Sensing Applications: Society and Environment 2020, 19, 100359.

13. Taloor, A.K.; Drinder Singh, M.; Chandra Kothyari, G. Retrieval of land surface temperature, normalized difference moisture index, normalized difference water index of the Ravi basin using Landsat data. Applied Computing and Geosciences 2021, 9, 100051

14. Shang, M.; Wang, S.-X.; Zhou, Y.; Du, C. Effects of Training Samples and Classifiers on Classification of Landsat-8 Imagery. Journal of the Indian Society of Remote Sensing 2018, 46, 1333-1340.

15. Li, C.; Wang, J.; Wang, L.; Hu, L.; Gong, P. Comparison of Classification Algorithms and Training Sample Sizes in Urban Land Classification with Landsat Thematic Mapper Imagery. Remote Sensing 2014, 6, 964-983.

16. Congalton, R.G.; Green, K. Assessing the Accuracy of Remotely Sensed Data - Principles and Practices Second edition; CRC Press, Taylor \& Francis Group: Boca Raton, NW, USA, 2009; p. 210.

17. Tortora, R.D. A Note on Sample Size Estimation for Multinomial Populations. American Statistician 1978, 32, 100-102.

18. Sobrino, J.A.; Jiménez-Muñoz, J.C.; Soria, G.; Romaguera, M.; Moreno, L.G.A.-J.; Plaza, A.; Martinez, P. Land Surface Emissivity Retrieval From Different VNIR and TIR Sensors IEEE Transactions on Geoscience and Remote Sensing 2008, 46, 316327.

19. Jiménez-Muñoz, J.C.; Sobrino, J.A. A generalized single-channel method for retrieving land surface temperature from remote sensing data. Journal of Geophysical Research 2003, 108, ACL 2-1.

20. Sobrino, J.A.; Jiménez-Muñoz, J.C.; Paolini, L. Land surface temperature retrieval from LANDSAT TM 5. Remote Sensing of Environment 2004, 90, 434-440.

21. Jiménez-Muñoz, J.C.; Cristobal, J.; Sobrino, J.A.; Soria, G.; Ninyerola, M.; Pons, X. Revision of the Single-Channel Algorithm for Land Surface Temperature Retrieval From Landsat ThermalInfrared Data. IEEE Transactions on Geoscience and Remote Sensing 2009, 47, 339-349.

22. Jiménez-Muñoz, J.C.; Sobrino, J.A.; Skoković, D.; Mattar, C.; Cristóbal, J. Land Surface Temperature Retrieval Methods From Landsat-8 Thermal Infrared Sensor Data. IEEE Geoscience and Remote Sensing Letters 2014, 11, 1840-1843.

23. Story, M.; Congalton, R.G. Accuracy Assessment: A User's Perspective. Photogrammetric Engineering and Remote Sensing 1986, 52, 397-399.

24. Rousta, I.; Sarif, M.O.; Gupta, R.D.; Olafsson, H.; Ranagalage, M.; Murayama, Y.; Zhang, H.; Mushore, T.D. Spatiotemporal Analysis of Land Use/Land Cover and Its Effects on Surface Urban Heat Island Using Landsat Data: A Case Study of Metropolitan 
City Tehran (1988-2018). Sustainability 2018, 10, 4433.

25. Ahmed, B.; Kamruzzaman, M.; Zhu, X.; Rahman, M.S.; Choi, K. Simulating Land Cover Changes and Their Impacts on Land Surface Temperature in Dhaka, Bangladesh. Remote Sensing 2013, 5, 5969-5998. 